\title{
The Methodology for the Creation of an Adapted Model for the Transition to the Circular Economy for the Small and Medium Enterprises of Latvia in a Long Term Perspective
}

\author{
Ivo Lemss \\ Faculty of Economics and Management \\ Ventspils University of Applied Sciences \\ Ventspils, Latvia \\ ivo.lemss@venta.lv
}

\author{
Una Libkovska \\ Faculty of Economics and Management \\ Ventspils University of Applied Sciences \\ Ventspils, Latvia \\ una.libkovska@venta.lv
}

\begin{abstract}
Research will focus on investments for the development of the company. Transition to the circular economy is understood in many cases only as an unnecessary obstacle, not as the new business model. Production based on the linear model "take, make, dispose of" is not possible anymore based on decreased environmental quality. Increased production efficiency could help promote the company's prestige, gain tax allowances, create optimistic co-operation with the state, municipality, and maintain sustainability in terms of the balance achieved between economic, environmental and social interests. Although the research until now is in an early stage, the research purpose is to create an adapted model for the implementation of the circular economy for the small and medium enterprises (from now on - SMEs) of Latvia in a long-term perspective. Research will focus on the following qualitative data analysis methods - SWOT, factor, economic contribution, structured interviews at expert level, overall structured interview in the form of the questionnaire. From quantitative methods, hierarchical cluster or partial cluster method will be used in this research, analysing 3966 organisations in the EcoManagement and audit scheme (from now on - EMAS) at the European level that ensure compliance with the essential environmental requirements under EMAS Regulation No.1221/2009 . Until now within the research, the number of EMAS organisations have been selected between 29 different countries (total number of observations) in 5 sectors (energy, water, waste management, food industry, port terminals), allowing to make the cross-country comparison and describe the involvement level of EMAS in each country. Before using the cluster method, it is essential to assess the cluster trend and whether the cluster method is suitable for research data. The next step will involve using a hierarchical cluster or partial cluster method (a certain number of clusters will be created). It is necessary to use different techniques to evaluate and interpret the created cluster results in future
\end{abstract}

work. Until now, the main conclusion from the literature study is that Latvia has no organisation registered under EMAS and the term "circular economy" is a prevalent trend nowadays worldwide, which can be justified with 114 different terms of the circular economy. Expected results will be the following - issued new criteria for SMEs, issued the adapted model and issued recommendations and suggestions for developing the eco-innovation market.

Keywords - circular economy, eco-innovations, industrial production, quality standards.

\section{INTRODUCTION}

It is an axiom that industrial production ensures the society with products and goods necessary for daily life; unfortunately, necessary investments for the development of the company, transition to the circular economy is understood in many cases only as an unnecessary obstacle (not opportunity), postponing, or even ignoring these issues. Production based on the linear model "take, make, dispose of" is not possible anymore based on decreased environmental quality (see Fig.1). Increased efficiency of the industrial production processes can help promote the company's prestige, gain tax allowances, create optimistic co-operation with the state, municipality sector and maintain sustainability (the balance between economic, environmental, and social interests) of the company activities. 


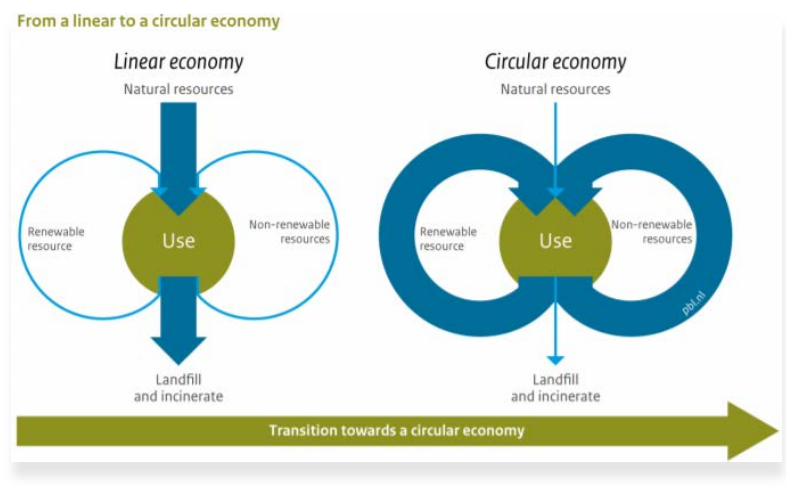

Fig.1. Circular economy concept [4].

The subject of the research is the different models of the circular economy. The object of the research will be SMEs in different economic sectors. The research hypothesis can be defined as the transition to the circular economy is the essential element to achieve high production efficiency in the companies in the long term perspective. The research aims to create an adapted model for the transition to the circular economy for Latvia's SMEs. Until now, the research covers five different essential sectors (electricity and heat production; water and sewage sector; waste management; food production; port terminals) for Latvia's economy, which can be justified with the significance of the infrastructure in each sector (see TABLE 1).

TABLE 1 GENERAL DATA SET IN EACH SECTOR [5], [6]

\begin{tabular}{|c|c|c|}
\hline Sector & $\begin{array}{c}\text { Total number of } \\
\text { companies in Latvia } \\
\text { (general data set) } \\
\text { by NACE codes }\end{array}$ & $\begin{array}{c}\text { Infrastructure / } \\
\text { activity }\end{array}$ \\
\hline $\begin{array}{c}\text { Electricity and } \\
\text { heat production }\end{array}$ & $\begin{array}{c}741 \\
\text { (NACE: } 35)\end{array}$ & $\begin{array}{c}\text { Central heat energy } \\
\text { supply systems }\end{array}$ \\
\hline $\begin{array}{c}\text { Water and } \\
\text { sewage sector }\end{array}$ & $\begin{array}{c}198 \\
\text { (NACE: } 36 ; 37)\end{array}$ & $\begin{array}{c}\text { Central water supply } \\
\text { and sewage systems }\end{array}$ \\
\hline $\begin{array}{c}\text { Waste } \\
\text { management }\end{array}$ & $\begin{array}{c}\text { Collecting, } \\
\text { transportation, } \\
\text { sorting, } \\
\text { regeneration, } \\
\text { landfilling }\end{array}$ \\
\hline Food production & $\begin{array}{c}\text { (NACE: } 38 ; 39) \\
\text { (NACE: } 10)\end{array}$ & $\begin{array}{c}\text { Production } \\
\text { technologies }\end{array}$ \\
\hline Port terminals & $\begin{array}{c}\text { The infrastructure of } \\
\text { the bulk and liquid } \\
\text { cargos }\end{array}$ \\
\hline
\end{tabular}

Tasks of the research are the following: 1 . To analyse literature in the field of environmental and circular economy and eco-innovation technologies; 2 . To prepare the methodology and organisation of the research; 3 . To compare the different elements of the circular economy (including EMAS and ISO); 4. To research small and medium enterprises based on different economic parameters in each of the sectors; 5 . To create and do a comprehensive questionnaire regarding the environmental policy implemented in a company for direct (companies, municipalities, state authorities) and indirect (students, citizens, NGOs) stakeholders; 6. To create and do structured expert interviews in order to assess the "portfolio" of the company, its aims, plans, development strategies, environmental policy; 7. To analyse and interpret data; 8. To create an adapted model of the circular economy for SMEs; $9 . \quad$ To create recommendations for the implementation of an adapted model of the circular economy.

The research topic will remain actual at least until 2025, which fully corresponds to Latvian "Action Plan for the Transition to a Circular Economy 2020-2027" and contributing to the implementation of the European Green Course and the global goals of sustainable development and stresses "(..) investment in research and innovation and support for the adaptation of industry and infrastructure (..)". The missing investments by 2025 are estimated at $€ 320$ billion [7].

Although several circular economy good practices have already implemented through eco-innovative projects in Latvia (treatment of the different type of the construction waste, plastics recycling etc.), there is still free capacity for many other projects. The research will use existing circular economy methodologies (for example, different checklists and questions) to strengthen both qualitative and quantitative methods.

\section{MATERIALS AND METHODS}

The research will use both qualitative and quantitative methods. The following qualitative methods will be used in research: 1. SWOT analysis (identification of the strength, weakness, opportunities, and threats of the circular economy); 2. FACTOR analysis (it is important to understand to what extent one factor can affect others if changes happen in one or another production process); 3. Economic contribution analysis (the gross changes in a region's existing economy can be attributed to a given industry, event, or policy [8]. In this research, economic contribution analysis could be used to analyse and assess whether after implementing some circular economy element, there occurs or there are not any changes in some particular sector; 4. Structured interviews at an expert level (at least three in-depth peer interviews in each sector to identify the most important and crucial points from SMEs point of view in terms of a possible implementation of at least one or more circular economy elements - what do they need? What are the main reasons/factors or obstacles that hinder the implementation of the circular economy? What should be done? et al.); 5. Overall structured interview in the form of the questionnaire (the aim is to ask the same questions to different stakeholders - companies, municipalities, state authorities, students, citizens, NGOs). After analysing the responses received, there will be clear in which questions there is consensus, but in which questions there are doubts, anger, negative emotions, different opinions. From quantitative methods, a hierarchical cluster or partial cluster method could be used in this research, analysing 3966 organisations in the EcoManagement and Audit Scheme (from now on - EMAS) at the European level that ensure compliance with the essential environmental requirements under EMAS Regulation No.1221/2009 [1]. Until now, within the research, the number of EMAS organisations have been 
selected between 29 different countries (total number of observations) in five sectors (energy, water, waste management, food industry, port terminals), allowing to make the cross-country comparison and describe the involvement level of EMAS in each country. Before using the cluster method, it is important to assess the cluster trend, whether the cluster method is suitable for the data used in research. If so, how many clusters could be formed? The next step will involve using a hierarchical cluster or partial cluster method (a certain number of clusters will be created). In future work, it is necessary to use different techniques to evaluate and interpret the created cluster results. If one chooses to use the cluster method in one's study, they will need to determine the optimal number of clusters to use, taking into account the statistical error [9]. Creating "K-medium" clusters is one of the simplest and most popular machine learning algorithms. Using an unknown algorithm, it is typical that conclusions are drawn from input vector datasets ("inputs") without reference to known or labelled results ("outcomes"). AndreyBu, who has more than five years of a machine learning experience, says that "The goal of Kmeans is simple: to the group, the same (with the same characteristics) data points together and discover the basic models. The K-mean uses fixed cluster numbers $(\mathrm{k})$ from the entire data set to achieve this goal. Defining the cluster numbers $(\mathrm{k})$ will record the number of centroids required throughout the data set. A centroid is an imaginary or real cluster centre. Each data point is assigned to each set by reducing the sum of the clusters' inner squares. In other words, the number of the centroid is identified $(\mathrm{k})$. In other words, the K-means algorithm identifies the $k$ number of centroids and then allocates every data point to the nearest cluster while keeping the centroids as small as possible. The 'means' in the K-means refers to averaging the data, finding the centroid. To process the learning data, the Kmeans algorithm in data mining starts with the first group of randomly selected centroids, which are used as the beginning points for every cluster, and then performs iterative (repetitive) calculations to optimise the positions of the centroids. It halts creating and optimising clusters when: the centroids have stabilised - there is no change in their values because the clustering has been successful; the defined number of iterations has been achieved [10]. Other quantitative methods as calculation of the internal rate of return (IRR) and other economic factors will be used in the research phases. The Likert scale method will be used to prove the hypothesis using respondents' attitude using an assumption that modernisation and development of the production are not possible without investments. Likert scales are the most broadly used method for scaling responses in survey studies. Survey questions that ask one to indicate their level of agreement, from strongly agree to disagree, use the Likert scale strongly. The data in the worksheet are five-point Likert scale data for two groups [11].

\section{RESULTS AND DISCUSSIONS}

With the circular economy's topic rapidly becoming popular in 2017, there are currently 114 different definitions found in various literature sources. One of the most popular definitions of the circular economy is that it is a production and consumption model that includes the extraction and distribution of resources, re-use, repair, refurbishment, and recycling of equipment to maximise the use of resources [12].

Selecting and getting acquainted with various scientific publications, exciting findings can be found in J.Tirole's research on innovations published in the Journal of Public Economics. At the same time, it should be emphasised that J.Tirole is considered to be a developer of the industrial economy. The research will substantiate the interdisciplinarity of the research with exciting findings from various articles on environmental issues and innovations; for example, J.Tirole concludes that the continuation of an existing activity without new investments is cheaper than new investments in new technologies because, in the last one, there is no state support in terms of different kind of allowances [13].

Expected results of the research will be the following issued new criteria for SMEs for the transition to the circular economy in long term perspective, issued the adapted model for SMEs for the transition to the circular economy and issued recommendations and suggestions for developing the eco-innovation market.

\section{CONCLUSIONS}

The main conclusion from the literature study is that Latvia has no organisation registered under EMAS [2], [3], and the term "circular economy" is a prevalent trend nowadays worldwide, which can be justified with 114 different terms of the circular economy.

In the following research, the author can conclude that it could be necessary to decrease the number of the sectors chosen because the circular economy's central sector is waste management, and other sectors where circular economy elements could be most appropriate is food production.

Practical application of the adapted model could be described as possible IT green market tool where wide range of the eco-innovations (technologies, standards, costs etc.) will be collected and sorted. Waste management and food production SMEs can use such tool for the appropriate analysis and decision making before investing.

\section{ACKNOWLEDGMENTS}

The author would like to thank Dr.sc.admin. Assoc. Prof. Una Libkovska for support.

\section{REFERENCES}

[1] Access to European Union Law, "Regulation (EC) No 1221/2009 of the European Parliament and of the Council of November 25, 2009, on the voluntary participation by organisations in a Community ecomanagement and audit scheme (EMAS), repealing Regulation (EC) No 761/2001 and Commission Decisions 2001/681/EC and 2006/193/EC", EUR-Lex-32009R1221-EN, 2009. [Online]. Available: EUR-Lex - 32009R1221 - EN - EUR-Lex (europa.eu). [Accessed: March. 14, 2021].

[2] Access to State Environmental Bureau. [Online]. Available: Vides pārraudzības Valsts birojs - EMAS - Reğistrs (vpvb.gov.lv). [Accessed: March. 14, 2021]. 


\section{Lemss, et al. The Methodology for the Creation of an Adapted Model for the Transition to the Circular}

Economy for the Small and Medium Enterprises of Latvia in Long Term Perspective

[3] Access to European Commission EMAS Register. [Online]. Available: Emas register (europa.eu). [Accessed: March. 14, 2021]

[4] J. Potting, M. Hekkert, E. Worrell. "Circular Economy: Measuring Innovation in the product chain" PBL Netherlands Environmental Assessment Agency, Hague, Netherlands, Policy Rep. p.9, 2017. [Online]. Available: https://www.pbl.nl/sites/default/files/downloads/pbl-2016-circulareconomy-measuring-innovation-in-product-chains-2544.pdf. [Accessed: March. 14, 2021]

[5] Access to Lursoft databases of enterprises. [Online]. Available: Lursoft - databases of enterprises. [Accessed: March. 14, 2021]

[6] Access to Enterprise Register. [Online]. Available: https://www.ur.gov.lv/en/register/. [Accessed: March. 14, 2021].

[7] Access to the Latvian policy planning document database [Online]. Available: Rīcības plāns pārejai uz aprites ekonomiku 2020.-2027.gadam POLSIS (mk.gov.lv). [Accessed: March. 14, 2021].

8] P. Watson, J. Wilson, D. Thilmany, S. Winter, "Determining Economic Contributions and Impacts: What is the difference and why do we care?" The Journal of Regional Analysis\&Policy, vol. 37(2), pp. 1-15, $2007 . \quad$ [Online]. Available: https://www.ntc.blm.gov/krc/uploads/74/Watson,\%20et\%20al\%20Impac ts\%20vs\%20Contribution\%2037-2-6.pdf. [Accessed: March. 14, 2021].

[9] A. Kassambara, "Practical Guide to Cluster Analysis in R," Multivariate analysis, vol.1, p.14-15, 2017. [E-book]. Available: STHDA, https://www.datanovia.com/en/wp-content/uploads/dn-tutorials/bookpreview/clustering en preview.pdf [Accessed March 14, 2021].

[10] M. Garbade, "Home page - Dr., Michael J.Garbade", September 2018. [Online]. Available: Understanding K-means Clustering in Machine Learning | by Dr. Michael J. Garbade | Towards Data Science [Accessed March 14, 2021]

[11] J. Winter, D. Dodou, "Five-Point Likert Items: t-test versus MannWhitney-Wilcoxon (Addendum added October 2012)," Practica Assessment, Research, and Evaluation: Vol. 15, 2010, Article 11. DOI: https://doi.org/10.7275/bj1p-ts64 Available: https://scholarworks.umass.edu/pare/vol15/iss1/11 [Accessed March 14, 2021]

[12] J. L. Ruiz-Real, J. Uribe-Toril, J. P. Valenciano, J. C. Gázquez-Abad, "Worldwide Research on Circular Economy and Environment: A Bibliometric Analysis," Int J Environ Res Public Health, 2018 November 29;15(12):2699 2018. DOI: 10.3390/ijerph15122699 Available: https://pubmed.ncbi.nlm.nih.gov/30501129/ [Accessed March 14, 2021].

[13] J. Laffont, J. Tirole, "Pollution permits and environmental innovation", Journal of Public Economics, 1996, Volume 62, Issues 1-2, Pages 127-140, https://doi.org/10.1016/0047-2727(96)01576-9 Available:

http://www.sciencedirect.com/science/article/pii/0047272796015769 Accessed March 14, 2021]. 